\title{
Leonard Savage, the Ellsberg Paradox and the Debate on Subjective Probabilities: Evidence from the Archives
}

This is the peer reviewed version of the following article:

Original:

Zappia, C. (2021). Leonard Savage, the Ellsberg Paradox and the Debate on Subjective Probabilities:

Evidence from the Archives. JOURNAL OF THE HISTORY OF ECONOMIC THOUGHT, 43(2), 169-192

[10.1017/S1053837220000152].

Availability:

This version is availablehttp://hdl.handle.net/11365/1120610

since 2020-11-19T19:37:44Z

Published:

DOI: $10.1017 / S 1053837220000152$

Terms of use:

Open Access

The terms and conditions for the reuse of this version of the manuscript are specified in the publishing policy. Works made available under a Creative Commons license can be used according to the terms and conditions of said license.

For all terms of use and more information see the publisher's website.

(Article begins on next page) 


\title{
LEONARD SAVAGE, THE ELLSBERG PARADOX AND THE DEBATE ON SUBJECTIVE PROBABILITIES: EVIDENCE FROM THE ARCHIVES.
}

\author{
BY CARLO ZAPPIA*
}

\begin{abstract}
This paper explores archival material concerning the reception of Leonard J. Savage's foundational work of rational choice theory in its subjective-Bayesian form. The focus is on the criticism raised in the early 1960s by Daniel Ellsberg, William Fellner and Cedric Smith, who were supporters of the newly developed subjective approach, but could not understand Savage's insistence on the strict version he shared with Bruno de Finetti. The episode is well-known, thanks to the so-called Ellsberg Paradox and the extensive reference made to it in current decision theory. But Savage's reaction to his critics has never been examined. Although Savage never really engaged with the issue in his published writings, the private exchange with Ellsberg and Fellner, and with de Finetti about how to deal with Smith, shows that Savage's attention to the generalization advocated by his correspondents was substantive. In particular, Savage's defence of the normative value of rational choice theory against counterexamples such as Ellsberg's did not prevent him from admitting that he would give careful consideration to a more realistic axiomatic system, should the critics be able to provide one.

* Dipartimento di Economia, Universita degli Studi di Siena. Contact: zappia@unisi.it
\end{abstract}

This "preprint" is the peer-reviewed and accepted typescript of an article that is forthcoming in revised form, after minor editorial changes, in the Journal of the History of Economic Thought (ISSN: 1053-8372), issue TBA. Copyright to the journal's articles is held by the History of Economics Society (HES), whose exclusive licensee and publisher for the journal is Cambridge University Press (https://www.cambridge.org/core/journals/journal-of-the-historyof-economic-thought ). This preprint may be used only for private research and study and is not to be distributed further.

The preprint may be cited as follows:

Zappia, Carlo. Leonard Savage, the Ellsberg Paradox and the Debate on Subjective Probabilities: Evidence from the Archives. Journal of the History of Economic Thought (forthcoming). Preprint at SocArXiv, osf.io/preprints/socarxiv 


\section{Acknowledgements}

A previous draft of this paper was presented at the STOREP Meeting in Catania (June 2016), at the D-TEA Meeting in Paris (June 2019) and at the HES Meeting in New York (June 2019). Comments by Marcello Basili, George Bent, Alain Chateauneuf, Alberto Feduzi, David Glasner, Itzhak Gilboa, Philippe Mongin, Aldo Montesano, Jochen Runde, Sam Savage, Francesco Sergi and three anonymous referees are gratefully acknowledged. Although his recollections of the details of his meetings with Savage are sparse, Daniel Ellsberg's suggestions were of fundamental importance. Usual caveats apply.

\section{INTRODUCTION}

Throughout the 20th century, economics has relied on a notion of rationality intended simply as consistency in preferences. While this notion of rationality was not novel in the early 1900 s it was only in the mid-1940s, with the birth of game theory, that the characterization of rational choice proposed by decision theorists became the mainstream view. Since John von Neumann and Oskar Morgenstern (1947) neoclassical economics has assumed that individual agents are able to attach probabilities to pay-off relevant events and to make decisions so as to maximize the expectation of a utility function relative to this probability distribution. But it was the mathematical statistician Leonard Savage (1954) who showed how to make it compelling that individuals should behave as though their beliefs were personal, subjective probabilities. As a result, the domain of rational choice theory was definitely thought to be extended from certainty to risk and uncertainty, the situation under which most real economic choices are made. Since then the traditional notion of homo economicus as utility maximizer has been replaced by that of a "Bayesian" decision-maker, whose preferences satisfy a few basic axioms and who is endorsed with a prior probability distribution over all possible events, to be updated according to Bayes's rule as new pieces of information arrive (Camerer 1995). 
As founder of what came to be known as the subjective-Bayesian viewpoint in decision theory, Savage was deeply involved in the development and defence of his approach. In the 1960s Savage published a series of contributions detailing the meaning of the subjective approach to probability and sponsoring its application to statistical practice. On the one hand, he confronted a statistical arena populated by sceptical, if not fiercely adverse, scholars who adhered to the conventional frequentist approach. With the help of his mentor Bruno de Finetti and a few other colleagues such as Irving J. Good and David Lindley, in a series of conciliatory, but unremitting contributions Savage (1962a, 1962b) dealt with the opposition coming from classical statisticians. Following on Abraham Wald's (1945) seminal idea that statistical problems should be solved as decision problems - that statistical practice needed a reorientation toward an economic approach to testing - in his Foundations of Statistics Savage had hoped to provide the subjectivist bases for traditional inferential statistics (Giocoli 2013). But on realizing that this was an impossible task, he insisted on the need for new instruments for statistical analysis, to be anchored on prior probability distributions, thus originating a revival of Bayes theorem and its applications (Edwards et al. 1963). Notwithstanding his efforts, the spreading of the Bayesian viewpoint in statistics was slow, never reaching the status of dominant approach in the field (Fienberg 2006).

On the other hand, Savage tried to make it clear the methodological bases of his approach to economic behavior and decision-making (Savage 1961, 1967a). Unlike statisticians, decision theorists wholeheartedly approved Savage's proposal to use subjective probabilities, specifically because his contribution clarified the axiomatic structure through which the notion of uncertainty could be reduced to that of risk, and then treated in the set-up conceived by von Neumann and Morgenstern for expected utility theory (Luce and Raiffa 1957). Notwithstanding early criticism by Maurice Allais (1953), the mainstream approval of subjective expected utility was so immediate that Savage did not have to defend it, making it possible for him to concentrate mostly on statistical issues in the crucial years before his sudden death in 1971. Indeed, Savage's perspective remains the mainstream view in rational choice theory and economics in general even today (Blume and Easley 2008). 
But despite general acclaim among economists (Arrow 1958, Hirshleifer 1965, Samuelson 1966), Savage's construct of an ideal rational agent able to maximise her subjective expected utility under both risk and uncertainty was made subject of what can be termed inside criticism. A few scholars who in principle accepted his subjective approach argued nonetheless that the behavioral bases of Savage's theory were shaky. Specifically, the subjective viewpoint had to confront a counterexample proposed by decision theorist Daniel Ellsberg (1961) who, using an approach similar to Allais's, devised simple decision problems in which decision-makers were shown to violate the axioms of subjective expected utility.

Today the relevance of the so-called Allais Paradox and Ellsberg Paradox is such that they are usual textbook reference, originating a substantial literature under the headings of non-expected utility theory (Machina 2008) and non-Bayesian decision theory (Gilboa and Marinacci 2013). In particular, the Ellsberg Paradox has become both the subject matter of experimental studies (Camerer and Weber 1992) and the fundamental starting point for almost every study aiming to show that decisions under uncertainty require a wider spectrum of rational decision criteria than the maximization of subjective expected utility (Gilboa 2009). ${ }^{1}$ Indeed, following on Ellsberg's claim, a very influential literature on ambiguity in decision making has tried to provide rational choice theory with new normative standards (Machina and Siniscalchi 2014, Gilboa 2015).

At the time, though, the impact of these paradoxical results was limited. Indeed, Savage had already rejected Allais's argument in a section of his foundational volume with the claim that he aimed at a normative theory of decision-making, one that could not be dismissed on the descriptive grounds suggested by Allais (1953). Savage's stance, that rational choice theory must be regarded as a normative, rather than descriptive theory of economic behavior, still holds, even in the claim of behavioral economists such as Kahneman (2003), who maintain that their own investigations-

\footnotetext{
1 A search for articles citing Ellsberg's 1961 paper in the single year 2019 using Google Scholar returns 545 references (search made on January 10, 2020).
} 
inspired by repeated observations that actual choices often contradict the theory-do not aim to question its normative validity. ${ }^{2}$

As for Ellsberg, his counterexample never received hearing in Savage's published contributions. Examining betting behavior in a series of urn examples, Ellsberg (1961) suggested that Savage's assumption that a single probability prior can always represent the decision-makers' degrees of belief was too restrictive, involving a significant misrepresentation of uncertainty. He shared with two other subjectivist scholars, economist William Fellner (1961) and statistician Cedric Smith (1961), the contention that the issue of vagueness cannot be eschewed from decision theory. Supporters of a strict subjective-Bayesian viewpoint such as Howard Raiffa (1961) and Harry Roberts (1963) insisted on the viability of Savage's solution to reduce uncertainty to risk, and despite replies by Ellsberg (1963) and Fellner (1963) the criticism did not hinder the subsequent spreading of the new mainstream in the specific variety devised by Savage. Largely, scholars working on both refinement and dissemination of the subjective-Bayesian approach to decision theory dismissed Ellsberg's critique as normatively irrelevant (Fishburn 1968, Raiffa 1968, Luce and Krantz 1971).

As just mentioned, Savage did not intervene in the debate sparked by his critics. Apart from some brief considerations about vagueness in decision-making — which he thought difficult to theorize about (Savage 1967b) — Savage never offered a proper analysis of what came to be known as the Ellsberg Paradox, apparently supporting Raiffa's rebuttal of Ellsberg's critique. This may explain why his reaction to the Ellsberg Paradox has never been examined. Compared with the

2 Throughout this paper, norms of behavior refer to action-guiding principles with prescriptive content (Hands 2012). A normative theory is not intended to state how people actually behave, but how they should behave if they wish to achieve certain aims. In decision theory the dichotomy between what is intended to be "descriptive" and what "normative" was first stressed by Marschak (1950). Luce and Raiffa (1957, p. 63) considered it "crucial that the social scientist recognize that game theory is not descriptive, but rather (conditionally) normative." 
substantial historical literature on the Allais Paradox (Jallais and Pradier 2005, Heukelom 2014, Mongin 2019), there are no historically oriented investigations of the debate on the Ellsberg Paradox. However, and while he was also concerned with Smith's (1961) version of the criticism, Savage devoted attention to the issue of imprecision in decision-making in a long joint paper with de Finetti written in Italian and never translated into English (de Finetti and Savage 1962). What is more, he corresponded with all his critics, and with de Finetti about how to deal with them.

This paper presents an assessment of the early 1960 debate, concentrating on Savage's reaction to the criticism coming from a small group of scholars who can be termed inside critics of the subjectivist approach. It provides a scrutiny of archival material, examining letters from Savage's private correspondence with de Finetti, Ellsberg and Fellner. ${ }^{3}$ This examination shows how Savage - jointly with de Finetti, who was often involved in the exchanges - reacted to the quest for generalization of the subjective viewpoint advocated by his correspondents. Apparently, Savage did not change his mind on the issue, even though his 1962 joint paper with de Finetti presents some significant concessions to Smith (Feduzi et al. 2014). But the correspondence examined in this paper suggests that Savage's viewpoint was more nuanced than he admitted in published works.

The paper tries to show that this is relevant for a history of decision theory at least on two grounds. First, archival material shows that Savage never denied, not even in his private exchange with de Finetti, to be a deliberate violator of his axioms while confronting Ellsberg's urns. This is a notable difference with respect to Savage's negative attitude towards Allais, on which the modern

3 The whole of the correspondence quoted in this paper is reproduced from the Leonard Jimmie Savage Papers, archived at the Manuscripts and Archives Department of Yale University Library (New Haven), as MS 695. In the following text, references will be made as follows: LJS Papers, Box \#, Folder \#. The assistance of Michael Frost and other staff members of the Public Services of the Manuscripts and Archives Department of Yale University Library is gratefully acknowledged. 
view of decision theory as normatively secure has been built. Second, and more relevantly, the correspondence shows that Savage was more open to a discussion about the normative appeal of his theory than usually assumed. Following on an approach he contributed to develop while in close contact with Jacob Marschak and Tjalling Koopmans - the call for rigor and mathematical precision characterizing the Cowles Commission for Research in Economics in the late 1940s and early 1950s (Koopmans 1957) - his position was that he would be ready to endorse a possible revision of his axiomatic structure, but only in view of a formally detailed alternative set-up, one that neither Ellsberg nor Fellner were able to provide.

As already noted, a significant criticism of normative kind that opposes the subjectiveBayesian approach is growing in current decision theory and applications (Gilboa et al. 2008). It has been claimed that the standard expected utility model, restricting attention to beliefs modelled by a single additive probability measure, is not convincing when there is no rational way to derive such well-defined beliefs. That is, in the presence of true uncertainty it fails to distinguish between probabilities based on reliable data and probabilities that result from significant ignorance about the environment in which decisions are made. When the individual agent is aware that important information is missing the rationality of the subjective-Bayesian approach is highly questionable and it is necessary to look for alternative normative standards. Since such an argument builds on Ellsberg's classic counterexample — and it was anticipated in the correspondence with Savage we shall examine - the analysis developed in this paper can suggest how Savage would have reacted to the current axiomatic developments recommending a substantial revision of the subjective-Bayesian approach (Gilboa and Marinacci 2013). ${ }^{4}$

4 Before moving on it should be noted that, although the subject matter of the debate was the socalled Bayesian position revived by Savage, Bayes's theorem did not have a role in the discussion. On the one hand, Savage did not make extensive use Bayes's formula in his Foundations, but only in his later research on applications (Edwards et al. 1963). On the other hand, the critics concentrated on the axiomatic set-up of the theory. The issue of how different 


\section{SAVAGE'S APPROACH}

As author of the first comprehensive presentation of what came to be known as the subjectiveBayesian viewpoint, in the late 1950s and 1960s Leonard Jimmie Savage (1917-1971) was widely regarded as its champion. ${ }^{5}$ Among decision theorists the axiomatic set-up of Savage's Foundations was immediately understood as providing the missing link between von Neumann and Morgenstern's expected utility theory—where probabilities are objectively given — and a treatment of uncertainty built on rationality principles. This was a long-awaited development by an entire community of scholars fostering a view of the rationality of agents as free from psychological assumptions, that is, not based on introspection, but behaviorally founded, derived from observed choices as in the revealed preference approach (Giocoli 2003, pp. 388-393).

axiomatic set-ups would impact on the dynamic consistency of choices never surfaced in the debate.

5 Trained as a mathematician, earning his Ph.D. at the University of Michigan in 1941, Savage began working in statistics during wartime at the Columbia University Statistical Research Group with Wald, but he was known among economists for his collaboration with Milton Friedman who he met when joining the University of Chicago in 1946. Friedman and Savage (1948) assessed the historical developments of the economic theory of risk in order to made apparent the significance of von Neumann and Morgenstern's (1947) axiomatic approach. Savage's main work in statistics was influenced by the call for rigor and conceptual precision that pervaded the Cowles Commission under Marschak and Koopmans, to which he was indirectly affiliated as member of the newly founded Department of Statistics at the University of Chicago, where he worked in the years from 1949 to 1960. 
Savage's main goal was to suggest an economic approach to statistics, to characterize statistics as a behavioral discipline, urging statisticians to embrace an economic way of reasoning when thinking about data. To do this, Savage (1954, p. 7) started off by building up "a highly idealized theory of the behavior of a 'rational' person with respect to decisions." As is well-know, Savage's main result was to demonstrate that an agent maximizing (subjective) expected utility is someone who can be thought as if obeying a few simple axioms on the set of actions - that Savage called "acts" - she can take, plus certain technical conditions. Together with completeness and transitivity, preferences over acts are assumed to conform to an independence axiom, dubbed the “sure-thing principle" by Savage. ${ }^{6}$ These axioms delimit individual preferences over acts whose consequences are dependent on the possible realization of events - in principle even singular events with no objective probability attached. Savage then showed that subjective probability distributions over events, satisfying the usual laws of probabilities, can be elicited from choices over acts. This made it possible to enlarge the domain of decision theory from risky situations such as lotteries to apparently every kind of uncertainty.

Already in 1951, on the basis of Savage's (1950) initial presentation of his ideas, Arrow had claimed that a new consensus was emerging about the behavioral significance of a distinction between risk and uncertainty. This was the view worked out at the Cowles Commission for Research in Economics in those years, where developing a "genuine science of economic behavior" implied to acknowledge that the problem of uncertainty should be addressed with renewed mathematical rigor (Cowles 1950-1951): theoretical research in decision-making under uncertainty

6 As presented by Savage (1967a, p. 306) in an effort to defend its plausibility, the sure-thing principle simply states that "if two acts have the same consequences for some states, the preference between the two acts will not be changed if they are given new common consequences on those states where they are already in agreement and each is left unaltered elsewhere." On the history of the independence axiom and the sure-thing principle see Fishburn and Wakker (1995) and Moscati (2016). 
became representative of a new methodological approach at Cowles, namely, abstract model building (Herfeld 2018, pp. 29-30). At Cowles scholars working on a varieties of areas, most notably general equilibrium theory, were moving beyond calculus towards new mathematical technics, concentrating on existence proofs and representation theorems (Duppe and Weintraub 2014).

As part of this methodological turn away from empirically oriented analysis and to normativism, Savage's axiomatization of decision-making showed the crucial fact that "Knight's uncertainties seem to have surprisingly many of the properties of ordinary probabilities" (Arrow 1951, p. 417). ${ }^{7}$ In their celebrated volume on games and decision theory, Luce and Raiffa (1957, p. 304) opened the chapter on individual decision-making under uncertainty with an endorsement of Savage's representation of the decision problem in terms of "states of nature," "acts," and "consequences." They praised the "elegant" feature of his approach that "no concept of objective probability is assumed; rather, a subjective probability measure arises as a consequence of his axioms." Savage (1961, p. 576) himself stated that, in the subjectivist viewpoint, probability simply is "an index, in an operational sense ..., of a person's opinion about an event." 8

7 As shown by Moscati (2016), Paul Samuelson, initially a severe critic, became a resolute supporter of expected utility theory after corresponding with Friedman and Savage on the normative value of an independence axiom. Friedman and Savage (1952) and Savage (1952) presented a preliminary version of the 1954 axiomatic set-up, making it apparent the normative appeal of grounding a theory of behavior under uncertainty on simple, reasonable axioms.

8 The emphasis on behaviorism, or operationalism à la Bridgman (1927), was intended to stress that concepts such as degrees of belief were not introspectively determined, as in the logical approach to probability of Keynes ([1921] 1973) and Jeffreys (1939), but defined in terms of the specific set of operations performed to measure them. De Finetti's ([1937] 1964) betting odds represented the way in which subjective probabilities could be thought as bases for consistent decision-making. A similar view was put forward independently by Ramsey ([1931] 1964), the 
As already noted, not even Maurice Allais's (1953) questioning about the descriptive validity of the theory had a negative impact on the diffusion of his theoretical corpus, since Savage (1954) had objected to Allais's critique that the normative content of the theory was untouched with respect to the choices of a rational individual. In response to Allais's (1953) critique of expected utility — and his own failure, as an experimental subject, to adhere to it when tested—Savage (1954, pp. 102-104) argued that theories of rational behavior have a normative status that is unquestionable even in the light of adverse evidence, which can only indicate "irrational" choices. As a matter of fact, his own experience as a violator was that a rational decision-maker who instinctively violates the theory when confronting Allais's example will reverse her choice after "thorough deliberation." In the early 1960s, then, the historical background of the subjective-Bayesian revolution is one that sees Savage's approach as amply accepted among decision theorists and favorably imported in economics to deal with microeconomic issues in general. Savage could then stay focused on what had actually been his main aim in the Foundations, that of showing how the subjective probability approach could strengthen Wald's (1945) viewpoint that every statistical

other founder of the subjective approach to probability. Behaviorism and subjectivism were the two key ingredients of Savage's project (Giocoli 2013).

9 As it is well-known, when tested by Allais at a meeting in Paris during the International Colloquium on Risk in May 1952, Savage expressed preferences contradicting his axioms. But after reformulating Allais's original problem, he later changed his mind and claimed that, in reversing his preferences, he corrected an "error." Savage (1954, p. 102) argued that "a person who has tentatively accepted a normative theory must conscientiously study situations in which the theory seems to lead him astray; he must decide for each by reflection ... whether to retain his initial impression of the situation or to accept the implications of the theory for it." So, only "deliberate" decisions must show consistency with the axioms of the theory. This defence of the normativity of rational choice theory has been termed a "quasi-empirical" test of rationality (Guala 2000). On the Savage-Allais correspondence, see Heukelom (2014). 
problem should be seen as a decision problem, to be solved by the statistician as if she was a rational decision-maker acting under uncertainty, the uncertainty related to the unknown probability distribution underlying the available data. On realizing that instead of providing stronger, behaviorally founded bases for traditional inference he had made it necessary to abandon standard inference techniques, Savage concentrated on the spread of new statistical tools and effective methods for inference (Giocoli 2013). ${ }^{10}$

For instance, his contribution to the Fourth Berkeley Symposium on Mathematical Statistics and Probability was a sort of manifesto for a paradigmatic shift in statistics: Savage objected to the way the traditional view of frequency probability had oriented statistical theory and concentrated on "another view [that] seems now to be entering upon the scene," the one that "may be called Bayesian or neo-Bayesian" (Savage 1961, p. 575). As a matter of fact, most of his efforts were directed at an unreceptive audience of frequentists such as George Barnard, Ronald Fisher, Jerzy Neyman and Egon Pearson, who endorsed a probability approach to statistical inference that was alien to a subjective view of the probability involved. ${ }^{11}$

10 As noted by a referee, Savage's attempt to find a compromise between tradition and innovation in statistics was acknowledged to be technically impossible in the years immediately after publication of the 1954 volume. Only after realizing this - a shift in understanding the depth of his research programme that Lindley (1980, p. 47) suggests happened around 1958 — Savage became a committed Bayesian. Savage's own recollection of his turn away from traditional inference is provided in the preface to the 1972 reprint of the 1954 volume.

11 The frequentist mainstream in statistics was of course a variegated one. For instance, Savage (1962c, p. 149) placed emphasis on Neyman and Pearson's insistence on behavior, rather than reasoning, while discussing induction, and claimed that "Bayesian statistics can be viewed as a continuation, rather than a contradiction of Neyman-Pearson theory." However, as testified by the discussion following Savage's (1962a) presentation of the subjective-Bayesian viewpoint at the Joint Statistics Seminar at Birkbeck and Imperial Colleges in London in 1959, the opposition 
Therefore, the majority of Savage's papers after the Foundations of Statistics were devoted to the illustration and defence of the new viewpoint in a quite hostile statistical arena (Lindley 1980). ${ }^{12}$ Since a relevant question in what follows is why Savage did not address in his publications the critical arguments made by a few critics among decision theorists, it can be argued that his resolve to stay focused on the diffusion of his creed among statisticians contributes to explain Savage's reluctance to get involved in a foundational debate.

\section{FRIENDLY FIRE IN ECONOMICS}

The symposium on "Decision under uncertainty," published in 1961 in the Quarterly Journal of Economics, made apparent both the status already gained by Savage's Foundations as the mainstream treatment of decision-making and a quest for its fundamental reorientation. Decision theorist Daniel Ellsberg (1961) and economist William Fellner (1961) examined Savage's subjective probability approach from the viewpoint of adherents to a well-structured theoretical corpus. Specifically, Ellsberg (1961, p. 657) argued that "the Savage axioms, and the general

to Foundations was almost unanimous among contemporary statisticians, with the notable exception of Irving Good and Cedric Smith.

12 Wallis (1981, pp. 22-23) remarks that the Chicago Statistics Department, which Savage helped create in 1949 — also by gathering a group of young statisticians, both as faculty members such as Harry Roberts and David Wallace, and as visiting scholars such as Dennis Lindley, Frederick Mosteller and John Pratt — and chaired from 1957 to 1960 before moving to the University of Michigan for personal reasons, rejected his request to come back in 1964. Savage interpreted this decision as indifference by his former colleagues to his radical new ideas. He then accepted the proposal by Yale to establish a new statistics department and spent the last few years of his life in New Haven. 
'Bayesian' approach, are unquestionably appropriate when a subject is willing to base his decisions on a definite and precise choice of a particular distribution," since in such a situation "his uncertainty ... is unequivocally in the form of 'risk'." But he also questioned Savage's approach on the grounds that it was not rich enough to deal with all instances of actual decision environments. Both Ellsberg and Fellner found that the reduction of decision-making under uncertainty into the framework von Neumann and Morgenstern (1944) had devised for risk was unwarranted: they disputed that all uncertainties could be reduced to risks. ${ }^{13}$

On the basis of observed violations by a number of colleagues he tested in the late 1950s at the RAND Corporation and Harvard Economics Department, Ellsberg, a Junior Fellow of the Harvard Society and RAND analyst since 1959, criticized Savage by claiming that vagueness about probabilities could lead individuals to violate the axioms of consistent behavior upon which Bayesian decision theory was based. Savage's sure-thing principle, in particular, was shown to be violated by individuals acting in what Ellsberg called "ambiguous" environments. Ellsberg's (1961, p. 646) claim was that, in a series of examples concerning choices from urns containing coloured balls, he was able to identify "a class of choice-situations in which many otherwise reasonable people neither wish nor tend to conform to the Savage postulates, nor to the other axiom sets that have been devised." What is more, Ellsberg suggested that, since in many cases the violations were deliberate - that is, individuals were not inclined to change their choices even after being asked to thoroughly reconsider the significance of the theory - the use of sharp probability priors could be

13 Following Knight (1921), Luce and Raiffa (1957, p. 13) identified decisions made under risk with a situation when know probabilities can be assigned to the states of the world in the state space, such as when playing roulette in a casino or buying lottery tickets. Uncertainty is typified as a situation in which this does not hold true: decisions have as their consequences a set of possible outcomes, but the probabilities of these outcomes are, unlike risk, unknown, such as when betting on horse races. 
inappropriate even from a normative point of view. In current economics literature these results are well-known as the Ellsberg Paradox. ${ }^{14}$

Fellner's (1961) argument was motivated on theoretical grounds. Fellner, a Professor of Economics at Yale University whose book on oligopolistic competition was one of the first to acknowledge the relevance of game theory, but who had been critical of the way von Neumann and Morgenstern dealt with the beliefs of the entrepreneur (Fellner 1949, p. 37-41), objected to the reasonableness of Savage's assumption. He argued that the observable decision weights that an individual attaches to prospective events - namely, the probabilities attached to an event if the individual actually bets on the event—may differ from the theoretical probabilities she would attach in Savage's set-up. When the individual regards some of her beliefs as "shaky judgements," Fellner maintained, subjective probabilities may be distorted, meaning that they would not obey the usual laws of probability, with the distortion depending on the perceived instability of certain judgements. Fellner concluded that this was to be expected in particular when events are unique, that is, when they do not belong to any "standard process" with objective characteristics. In these cases, "we should not regard it as irrational if a person develops a reaction to uncertainty rather than is guided exclusively by mathematical expectations" (Fellner 1961, p. 685). The similarity with Ellsberg's was apparent, since Ellsberg had distinguished unambiguous from ambiguous urns, claiming that people usually prefer to bet on an unambiguous urn with respect to an ambiguous one even though the subjective probability attributed to them by Savage's approach was supposed to be the same. ${ }^{15}$

14 The extent to which Ellsberg insisted on the normative falsification of Savage's view, a point largely disregarded in current decision theory, is examined in Zappia (2018).

15 Although long unaddressed, Ellsberg's urn examples and Fellner's intuition were crucial for subsequent developments providing an alternative axiomatic structure for decision-makingbased on multiple and non-additive probability priors - in what is usually called the ambiguity literature (Gilboa 2009; Machina and Siniscalchi 2014). Among an increasing number of applications, Nobel Prize laureates Lars Hansen and Thomas Sargent endorsed this view in their 
The QJE symposium had Howard Raiffa arguing in favor of Savage's approach. Raiffa, a mathematical statistician at Harvard University who was developing new mathematical tools for applied business decisions from a subjective viewpoint (Raiffa and Schlaifer 1961), reaffirmed his faith in Savage's axioms as normative guides. ${ }^{16}$ Referring to experimental sessions he conducted using adaptations of Ellsberg's example, Raiffa (1961, pp. 692-693) admitted that "if certain uncertainties in the problem were in a cloudy or fuzzy form, then very often there was a shifting of gears and no effort at all was made to think deliberately and reflectively about the problem," confirming the experience of Ellsberg and Fellner. However, the message he drew was different from theirs. Ellsberg's choice examples simply showed, in his view, that "there is a need to teach people how to cope with uncertainty in a purposive and reflective manner." Raiffa reported that experimental subjects who were initially inclined to violate the axioms behaved consistently with them when suggested a different way of looking at Ellsberg's problems.

It is worth noting that the Allais-Savage debate was not referred to by any of those participating to this new round of debate: Allais's (1953) criticism focused on utility axioms in an unambiguous context with objective probabilities — a situation of risk-while the concern now was the limitations of probability axioms in contexts in which only subjective probabilities were available - a situation of uncertainty. But Raiffa implicitly assumed Savage's solution to Allais as the conventional way to deal with hypothetical examples: in the experimental sessions he

studies on the potential misspecification of macroeconomic policy models under uncertainty (Hansen 2014).

16 It must be remarked the Raiffa and Schlaifer (1961) presented subjective expected utility as the theory of decision-making for business studies, a normative guide for practical behavior, showing that Savage's original goal to provide a normative guide for statisticians had already transcended to business applications. 
conducted, Raiffa presented to his subjects Ellsberg's urn problems in a rearranged table form, similarly to what Savage had done (1954, p. 103) when examining Allais's example. ${ }^{17}$

As is well-known, the mainstream endorsed Raiffa's rejection of Ellsberg, whose paradoxical results had to wait more than twenty years to be addressed consistently in decision theory (Schmeidler 1989). But Savage was not involved in the defence of his approach against Ellsberg and Fellner. Quite probably this was because, as noted above and as the correspondence we shall examine later confirms, he was consumed by the debate in what he perceived as the much more relevant statistical arena. As a matter of fact, in Savage's published works only a few words are dedicated to Ellsberg's and Fellner's criticism. Savage's annotated bibliography prepared for the second edition of the Foundations of Statistics presents the 1961 QJE Symposium as "an account of an important line of dissent from the theory of personal probability and utility" (Savage 1970, p. 25). ${ }^{18}$ Savage (1970, p. 24) also acknowledges that de Finetti and Savage (1962) "discuss a large number of doubts and difficulties about the actual application of personal probability:" in fact, the notion of interval-valued, as opposed to sharp, probability prior is examined at length in de Finetti and Savage's 1962 paper. But neither Ellsberg nor Fellner are mentioned in that paper.

Before turning to what the correspondence shows, it is worth recalling that Savage had already faced the issue of vagueness, in both his Foundations and later contributions. Indeed, we shall see that the private discussion with his critics is reminiscent of a distinction between sure and

17 Ellsberg's counterargument, that Raiffa's reformulation of his problems suppressed significant information in the original data, was provided in his doctoral thesis (Ellsberg [1962] 2001, pp. 241-246). The fact that Ellberg did not publish his thesis before being definitely absorbed in his role as strategic analyst at RAND and the U.S. Department of Defence contributed to his defeat. Ellsberg (2002) provides a memoir of his sudden turn away from academics and involvement in the Vietnam War and the diffusion of the so-called Pentagon Papers.

18 Savage (1954, p. 3) preferred to call "personal" the probabilities of what came to be known as the "subjective" probability approach. 
unsure opinions Savage (1954, p. 58) had examined in his Foundations concluding: "The notion of 'sure' and 'unsure' ... is vague, and my complaint is precisely that neither the theory of personal probability, as it is developed in this book, nor any other device known to me render the notion less vague." Later, in what can be seen as an unspoken reference to Ellsberg, Savage (1962b, 165) remarked: "some people see the vagueness phenomenon as an objection [to precise personal probabilities]; I see it as a truth, sometimes unpleasant but not to be escaped by a new theory." And when discussing certain "difficulties" in the theory of personal probability he argued: "Some have tried to reflect the phenomenon of vagueness within the theory, while others believe that, though vagueness must somehow be reckoned with, its nature defies formalization" (Savage 1967a, p. 308).

In view of Savage's commitment to the mathematical rigor sponsored at Cowles - namely, to provide a set of rules constraining the decision-maker's choices - the issue of whether the critics would be able to propose a formalized version of their suggestions is crucial in the correspondence to which we now turn. As a matter of fact, only critiques amenable to formalization, showing themselves operationally founded, would have caught Savage's attention. He had indeed insisted from the outset that his theory was not about "what to believe in the face of inconclusive evidence, but ... what action to decide upon such circumstances" (Savage 1954, p. 2).

\section{ARCHIVAL EVIDENCE: FIRST PART}

This section presents the private correspondence between Savage and Ellsberg and Fellner, two professed subjective-Bayesians who ended up as critics of the strict version of the approach. The correspondence is illustrative of Savage's interest in the topic of vagueness and imprecision in probability priors as a possible generalization of his viewpoint. The main theme that emerges is that Savage did not formulate an outright rejection of the criticism, unlike what he had done when he had to confront Allais's (1953) critiques. One may be tempted to argue that the fact that Savage did 
not publicly reply to Ellsberg's counterexamples should be interpreted as showing that he did not attribute to Ellsberg any significant advance as compared with what he had judged as Allais's inability to disqualify the normative status of the theory. But the exchange with Ellsberg and Fellner shows instead a more open attitude towards the alleged violations. Rather than a clear cut denial of interest toward the normative impact of Ellsberg's suggested violations, Savage seems to show an unwillingness to endorse a less firm subjectivist perspective while still fighting for the acceptance of the core of his viewpoint in the statistical arena.

Ellsberg was explicit about his attempt to influence the subjectivist developments. In his doctoral thesis at Harvard-unpublished for many years but circulated among major contributors to decision theory, including Savage and de Finetti_Ellsberg ([1962] 2001, xlix) acknowledged that "nearly every page of this study testifies to my intellectual debt to L. J. Savage," to whom he was grateful "for encouraging me to believe that the arguments and counterexamples presented here deserved serious consideration." Ellsberg's claim, never objected to by Savage—neither in his published writings nor in the available archived correspondence- - is that Savage was among deliberate violators of his own axioms when tested in February 1958 (Ellsberg 1961, p. 654).

However, Ellsberg defined himself a "less exacting 'neo-Bayesian'” in the footsteps of Good (1952) (Ellsberg [1962] 2001, p. 165) and presented his comments on Savage's Foundations as “mainly critical, and by some standards heretical with respect to 'Bayesian' principles.” Ellsberg made it clear that the thesis was addressed mostly to "the currently convinced" of the subjectiveBayesian view, and claimed: "very simply: I wish to change their minds ... I hope ... to persuade them there are more ways of being reasonable under uncertainty than they currently imagine" (Ellsberg [1962] 2001, p. liii). ${ }^{19}$ While sending him the thesis manuscript a few days before its defence, in his accompanying letter Ellsberg confesses to Savage:

19 On Ellsberg's arguments in favor of a generalized version of the Bayesian approach in his thesis see Levi (2001) and Zappia (2016). Binmore (2009) provides an assessment of Savage's approach from an Ellsbergian perspective. 
I see from a copy of your letter to Fellner that I haven't convinced you yet. That is just as well, since the enclosed manuscript (which is really a 400-page letter to you, designed to change your mind) would hardly have been worth the trouble.

(D. Ellsberg to L.J. Savage, May 21, 1962, LJS Papers, 11, 260)

The correspondence collected at Yale University contains only a few letters (ranging from 1961 to 1963 ) and is surely not exhaustive about the debate among the two, who personally met a few times in the meantime. ${ }^{20}$ The correspondence had started on October 1961 with Savage's acknowledgement of receipt of the QJE paper sent to him by Ellsberg and his suggestion to forward it to de Finetti, as he often did with correspondents. But there is no evidence that the comments promised by Savage to Ellsberg - in the hope they would arrive "soon enough to affect your thesis, insofar you find them pertinent” (L. J. Savage to D. Ellsberg, February 18, 1962, LJS Papers, 11, 260)—were ever written. ${ }^{21}$ However, even in the absence of a proper answer to Ellsberg, the exchange with de Finetti is illustrative of Savage's attitude. ${ }^{22}$ Early in 1962 de Finetti asks Savage:

20 The two surely met to discuss Ellsberg's theory at least once in March 1962, while Ellsberg was writing his thesis, submitted in April 1962. The correspondence alludes also to what appears to be their last meeting in May 1963. Savage was on the verge to move to New Haven, while Ellsberg had already become heavily involved in his activity as military analyst for the US Defense Department (Ellsberg 2002).

${ }^{21}$ Unfortunately, Ellsberg has no detailed recollection of his meetings with Savage and does not remind whether he ever received written comments from him (personal communication, email dated September 6, 2016).

22 As we shall see, the exchange between Savage and de Finetti was constant and significant. They had been corresponding since the early 1950s and de Finetti's presentation at the Second Berkeley Symposium on Mathematical Statistics (de Finetti 1951). Savage was knowledgeable in Italian, so de Finetti could write him in his native language. In the early 1960s, after Savage 
Have you read D. Ellsberg's note (Quarterly J. of Econ., 75,4, Nov. 1961) that claims that you were 'inconsistent' in answering to one of his questions concerning issues such as Smith's?"

(B. de Finetti to L. J. Savage, March 8, 1962, LJS Papers, 8, 194, author's translation from the original Italian)

In his reply, Savage states:

I have not only read Ellsberg's paper but had a very thorough visit with him here in Ann Arbor. He is intelligent, steeped in the material, but quite blind about certain aspects of it. I feel that there may be a grain of truth in what he is trying to say, but find it very difficult to clear my own head on the subject.

(L. J. Savage to B. de Finetti, March 16, 1962, LJS Papers, Box 8, 194)

We shall see that the reference made by Ellsberg to a letter to Fellner helps understand Savage's reaction. But it is enlightening that after receiving the thesis Savage urged Ellsberg to send his manuscript to de Finetti, as he had already done with the $Q J E$ article. Later in 1962, de Finetti provided his comments in a letter to Ellsberg, forwarded to Savage. De Finetti's reaction to Ellsberg's thesis is closely adherent to the subjective-Bayesian canon, that is thoroughly defended. But after pointing out that overall his position was "essentially the same as Raiffa's," de Finetti comments on the maximization of expected utility, that he was used to attribute to Bernoulli:

I am not inflexible against violators of Bernoullian rule ... This criterion is not a moral law, but simply a distinction between decision rules having and having not a surely desirable property (admissibility); I will deny any reason (if not mathematically disproving the now established Bernoulli/Ramsey/Savage theory) to admit other Criteria than the one "rational," but I admit many reasons justifying people not willing to follow (in particular senses and cases) the "rational criterion" ... [especially because] many complementary aspects are ignored in the mathematical formulation of the goal-function and it is more convenient to take them into account empirically.

(B. de Finetti to D. Ellsberg, Aug 21, 1962, LJS Papers, 8, 195)

spent a sabbatical in Rome in academic year 1958-1959, the correspondence became huge, containing dozens of letters each year. 
Notwithstanding the unsystematic content of the correspondence with Ellsberg two things are worth noting before moving on to that with Fellner. First, Savage did not take the opportunity given to him by de Finetti to deny the normative significance of his own violations, as actual decision-maker, of the axioms: he did not object, not even in private, to being classified as a deliberate violator of his own axioms by Ellsberg. While of course this cannot but be speculative, we may take this episode as signalling that Savage was more intrigued by the significance of the empirical violation put forward by Ellsberg than he was with respect to Allais's. Second, while de Finetti used the descriptive/normative distinction in his comments on Ellsberg's thesis to reject his counterexamples as normatively irrelevant, he contemplated the issue of normative violation. Under the strict condition that a normative counterargument could be taken into account only if “mathematically disproving” the subjective-Bayesian approach, de Finetti admitted that a normative argument against the subjective approach could be of interest.

As already mentioned, there is evidence of Savage's own reaction to Ellsberg in his exchange with Fellner. Late in 1961, Fellner had asked Savage to comment on his idea of probability distortions in the face of uncertainty, emphasizing the similarity with Ellsberg's experimental results. Apologizing for not being ready yet to offer a detailed comment on his $Q J E$ paper because of other obligations, Savage replies to Fellner in the letter mentioned by Ellsberg: I had long and serious conversations with Ellsberg in which I am sure I tried sincerely to grasp his point of view, but I emerged with the feeling that his ideas do not represent a step forward from such theories as those expressed in my book, for the normative purpose in which I am interested. Your paper may give me a different slant; we cannot know until I find time to study it. ... In particular, I am now very much interested in exploring the implications of the conventional theory of subjective probability for everyday technical statistics. ... . If the theories of subjective probability, as I understand it, is seriously deficient, these deficiencies will express themselves in my statistical theories. But I think that you and Ellsberg would not question that this theory has promise as a sort of first approximation and deserves to be explored at least on that account.

(L. J. Savage to W. J. Fellner, May 10, 1962, LJS Papers, 11, 267) 
Savage had taken months to reply to Fellner, pointing to the fact we have already mentioned that his research was devoted to developments in statistical practice rather than foundational issues. Indeed, while trying to convince statisticians that they should use a prior probability in every examination of data, it would have been counterproductive for his approach to admit that this prior can be vague in certain instances of relevance. But Fellner immediately insisted on his point, namely, the cognitive unease of dealing with uncertainty issues as if they were risky ones:

Many people feel differently about staking their fortunes on controversial judgments from how they feel about taking a chance on de facto uncontroversial ones. ... in contrast to Raiffa, I have found in recent experiments that a good many very intelligent individuals do not in fact get rid of this inclination, even if the experimenter exposes them quite impartially to both sides of the controversy. ... The normative proposition that a person is not entitled to this reaction seems arbitrary to me.

(W. J. Fellner to L. J. Savage, May 15, 1962, LJS Papers, 11, 267, italics in the original)

Even this time, Savage was not eager to answer soon. The idea to abandon, or even relax, his main assumption that precise subjective probabilities can be determined and used in every decision problem, while still trying to convince statisticians to follow him in statistical practice, was certainly not on his agenda. But in a reply dated June 1963, the issue raised by Fellner in his letter - and in particular a summary of his argument Fellner had enclosed in it —is re-examined:

[Your summary] says that a certain normative assumption seems arbitrary to you ... Would it not be a step forward in science, and in our conversation, if you were to decide which assumptions in F. of S. seem arbitrary. ... A normative proposition maybe unsatisfactory without being arbitrary, and the assumptions in F. of S. are certainly unsatisfactory to me in certain ways, though they are still almost the best I know how to propose. ... You may say “... let us make assumptions that are more nearly right." I sympathize. In fact, I do in effect make more nearly correct assumption in practice. What I do not know how to do is to make a mathematical theory with more realistic assumptions (L. J. Savage to W. J. Fellner, June 17, 1963, LJS Papers, 11, 267)

And when Fellner pointed at the sure-thing axiom, as the arbitrary assumption, Savage replies: If I understand correctly, the essential point here is whether the original imperfect system exemplified by F. of S. admits mathematical improvement or only improvement by informal 
commentary. I have expressed a pessimistic opinion about the possibility of the latter, but I trust I would not be blind to a better system should one come along.

(L. J. Savage to W. J. Fellner, July $1^{\text {st }}$, 1963, LJS Papers, 11, 267)

It must be stressed then that the issue explicitly became whether or not normative progress was possible. Although it appears that Savage no longer showed interest in Fellner's attempt to discuss a generalization of his viewpoint allowing for vagueness, ${ }^{23}$ the correspondence shows that Savage may have accepted a constructive criticism of his theory, possibly generating a new normative standard, but with the caveat that the new theory were able to provide theoretical continuity in terms of the way his one was formulated, namely, its axiomatic structure.

In conclusion, the early 1960s exchange with Ellsberg and Fellner signals a positive attitude by Savage (and de Finetti) towards the significance of their criticism. This is not surprising on descriptive grounds: indeed, in those years both Savage and de Finetti had been insisting that theirs was a normative viewpoint, and that descriptive violations were plainly admitted. As already remarked, the axiomatic structure devised by Savage in his Foundations was explicitly intended to provide a normative guide to the formation of consistent beliefs by statisticians. Axioms are instrumental, Savage (1954, p. 20) claimed, "to police my own decision for consistency, and, where possible, to make complicated decision depend on simpler ones."24

${ }^{23}$ In a letter of August 1963, Feller insisted that the phenomenon of imprecision could be addressed by a new theory, but could not provide any axiomatic justification for his point. It is then not surprising that the Leonard Jimmie Savage Papers do not contain any further letter from Savage to Fellner, although this absence could also be explained by Savage's 1964 move to New Haven where Fellner was Sterling Professor of Economics and they may have met.

${ }_{24}$ As for de Finetti, an editorial note he added to the 1964 English translation of his 1937 classiccommenting on his original claim that the rules of probability calculus are applied, albeit unconsciously, "by all men in all circumstances of life" - reads as follows: "in order to avoid frequent misunderstandings it is essential to point out that probability theory is not an attempt to 
But the correspondence also shows that, while they kept objecting to the possible normative relevance of the specific arguments raised by their critics, Savage and de Finetti considered the normative issue worth discussing. They both showed a more open attitude than they were used to do in their published works. We have seen, on the one hand, de Finetti asking for a negative argument of mathematical kind, that he considered as a prerequisite to openly consider Ellsberg's point as of normative value. On the other hand, in his quest to Fellner for axioms apt to replace the sure-thing principle, Savage admitted that a constructive argument would be of interest, in so far as "mathematical improvement" was in principle acceptable.

To be sure, both Savage and de Finetti insisted that more realistic hypotheses should not be detrimental to the normative appeal of the entire axiomatic structure of the subjective approach to decision-making: in particular, Savage would not abandon a normative proposition such as the surething principle — which may appear "unsatisfactory without being arbitrary" —in absence of an alternative proposition endowed with similar plausibility. But it is remarkable that in the discussion with Ellsberg and Fellner a possible generalization of the subjective-Bayesian approach-officially denied in print, while still fighting for acceptance among statisticians — was contemplated. And, indeed, this is the route followed in decision theory in the 1980s after the experimental evidence confirming Ellsberg's results became overwhelming and started being interpreted as of normative value. $^{25}$

describe actual behavior; its subject is coherent behavior, and the fact that people are only more or less coherent is inessential" (de Finetti [1937] 1964, p. 111).

25 Schmeidler's (1989) axiom of comonotonic independence among acts — on which Choquet expected utility theory with non-additive probability priors is based—arguably represents the kind of replacement Savage may have requested. On the normative appeal of the current developments in rational choice theory rejecting a strict version of Bayesianism, see Gilboa (2015). 


\section{FRIENDLY FIRE IN STATISTICS}

As seen in the previous section, both Ellsberg and Fellner aimed at a normative criticism of Savage's viewpoint, one that could not simply be classified as a descriptive violation of rational choice theory. The attention they received from Savage in private exchange was substantial, but ineffective: Savage never really tackled the issue they raised in his publications. Although his counterexamples proved to be puzzling for Savage, Ellsberg's aim "to change" Savage's mind failed: the correspondence reveals that neither he nor Fellner were able to provide the requested alternative axiomatic set-up.

This section presents excerpts from the archival evidence available on a distinct, but related criticism, that suggested by Cedric Smith (1961) with his study on upper and lower probability values in a Bayesian framework. Mostly through an analysis of the thoughts shared with de Finetti while examining Smith's point, Savage's understanding of vagueness and possibly imprecise probability priors can be detailed as subtler than usually understood, confirming the evidence already examined on the Ellsberg Paradox.

As we have seen, a core aspect of Savage's subjective research programme was the possibility to provide a behavioral justification of the representation of degrees of belief as probabilities, that is, an operationally founded — in Bridgman's (1927) sense — subjective probability. This step toward behaviorism, refraining from introspection, had been proposed by Ramsey and de Finetti in terms of betting quotients elicited from choices, plus a condition of consistency, usually interpreted as the impossibility to have a "Dutch Book" made against a rational individual. A crucial argument against accepting the vagueness of beliefs Ellsberg and Fellner 
wanted to allow, in order to deal with what they considered a kind of uncertainty irreducible to risk, was that it would be incompatible with this elicitation procedure. ${ }^{26}$

In their criticism, both Ellsberg and Fellner referred to this aspect. Ellsberg, in particular, devoted an entire section of his doctoral thesis to de Finetti's "condition of coherence." For purposes of measurement, de Finetti ([1937] 1964) had regarded probabilities as "prices" and assumed that the highest price an individual is ready to pay for betting in favor of an event — her probability for the realization of the event as a bettor-coincides with the lowest she is ready to accept for taking the other side of the bet—-her probability as a bookie. In order to derive a sharp subjective prior satisfying the laws of probability, therefore, no inequality between upper and lower betting prices was allowed by de Finetti. Ellsberg accepted the subjectivists methodology of eliciting probability from choices, but he argued that he could see no rationale for the assumption that the decision-maker is always willing to take either side of a bet at the same price, as implied by de Finetti's reasoning (Ellsberg [1962] 2001, p. 68). And in order to clarify his point Ellsberg referred to the approach of deriving lower and upper probability priors from betting presented by Smith (1961).

Cedric Smith, a statistician at the Galton Laboratory of the University College, London, who specialized in genetics, was among the very few English statisticians endorsing Savage's subjectiveBayesian perspective from the outset. But Smith's 1961 paper also belonged to the tradition of interval-valued probabilities, an approach that had been investigated by probabilists such as Bernard

26 The issue of consistency in betting was popularized through the so-called Dutch Book argument, that refers to a betting situations designed by a bookie so that a bettor accepting the offered betting prizes loses, no matter how events turn out. De Finetti ([1937] 1964, p. 103) showed that in order to be immune to Dutch Books the subjective probabilities of an individual had to satisfy the basic properties of a probability measure. Kyburg (1978, p. 159) described the Dutch Book argument as a "fundamental nexus" in which logic and behavior meet in the subjectivist interpretation of probability. 
Koopman (1940) and Good (1952), who had worked in the footsteps of Keynes's ([1921] 1973)

notion of epistemic probability and his hint that probabilities might be ordered only partially. ${ }^{27}$ But while Koopman and Good interpreted probabilities simply as "intuitive judgements," that is, judgements based on introspection prior to objective experience, Smith followed de Finetti in adopting a behavioral perspective. He accepted that subjective beliefs are meaningful only if measured by means of the elicitation of probabilities from betting quotients accepted by individual agents in controlled environments, as in de Finetti ([1937] 1964). But he applied this procedure to derive possibly imprecise beliefs. He showed how to elicit from personal betting quotients upper and lower probability values, and clarified the formal conditions under which the decision-maker can then be attributed an interval of precise initial probabilities. As a result, Smith showed that a decision-maker refusing to bet on either an event or its complement can do so consistently, in de Finetti's sense. ${ }^{28}$

Ellsberg used Smith's analysis to argue that the probabilities that can be derived from the choices of a deliberate violator of Savage axioms in his urn examples define an interval of probabilities, but cannot be termed "irrational" by means of the Dutch Book argument. Indeed,

27 The primacy of Keynes's Treatise on Probability in introducing the issue that epistemic probabilities may be "non numerical" (i.e., not sharply determined) and that confidence in a probability assessment may vary, was admitted by Ellsberg in his doctoral thesis. On Keynes's role in the philosophy of probability see Gillies (2000).

28 Smith illustrated his viewpoint as follows: "if I am willing to bet 2 to 1 on sun against rain, and 1 to 4 on rain against sun, this means that I regard sun as between 2 and 4 times as probable as rain; and I do not need to be more precise than this." As a result, the elicitation of probabilities from choices entails that "probabilities and utilities are no longer uniquely defined, but, in accordance with human vagueness and imprecision, they are only determined within a certain range" (Smith 1965, p. 478). For an analysis of Smith's role in the development of the imprecise probability approach in statistics see Walley (1991). 
consistency does not apply only to a set of "precise, definite beliefs," since "beliefs that must be treated as 'indefinite' within limits can still be precise enough to determine decisions in betting, and susceptible of quantitative expression in terms of inequalities" (Ellsberg [1962] 2001, p. 88).

\section{ARCHIVAL EVIDENCE: SECOND PART}

We have seen earlier that de Finetti mentioned Smith when asking Savage about Ellsberg, in his letter of March 1962. And, indeed, in the early 1960s de Finetti and Savage were discussing about how to react to Smith's proposal to generalize the subjective-Bayesian approach in order to allow for interval-valued probability priors. The correspondence between them on this point-mostly related to the drafting of de Finetti and Savage (1962), a joint paper they were working on—reveals the extent to which interval-valued probabilities could be contemplated. It is also interesting because the tension already emerged in the discussion with Ellsberg and Fellner between what is descriptively versus normatively relevant is even more evident in light of Smith's argument.

De Finetti and Savage's (1962) paper, titled "Sul modo di scegliere le probabilità iniziali" (How to choose the initial probabilities) was intended for a statistical audience. It presents to statisticians a summary of why, in their view, no problem can be correctly stated in statistics without an evaluation of the "initial probabilities." But it also reflects the two subjectivist scholars' perplexity with respect to the statement they were publicly defending, namely, that the reference to intervals of prior probabilities may pose "more severe problems that they are intended to resolve" (Savage 1962c, p. 150). ${ }^{29}$

29 The paper was not translated into English, and was known among Bayesians only through a long English summary written by Savage (1962c). But Savage's English summary was written before de Finetti, on Savage's request, drafted the additional section on Smith to which the correspondence examined in this section refers. Therefore, the content of the section devoted to 
Savage's correspondence with de Finetti shows that it was on Savage's request that Smith's contribution was made a subject matter of their investigation. While commenting on the translation into English of a piece by de Finetti, Savage had written:

I wondered whether before concluding on page 65 [of your Lectures] you would want to touch on the allegorical idea of many opinions in one person à la Smith. Also, it is less allegorical and to that extent more satisfactory, to speak of the many systems of opinion not altogether incompatible with the vaguely defined system of a real person.

(L. J. Savage to B. de Finetti, March 3rd, 1961, LJS Papers, 7, 192)

Savage seems to suggest that Smith's interpretation provides a technical, rather than simply metaphorical, way to introduce the issue of vagueness, and that this makes it worth examining (see also Savage 1962d). And, indeed, his concern about imprecise probability priors is reflected in the section of the paper dedicated to Smith that reproduces part of the correspondence between the two authors ensuing from a preliminary draft. In particular, in a letter to de Finetti, Savage is reported to claim:

we seem to argue [in the preliminary draft] that imprecision in probability judgements can be always removed, after providing enough effort ... [but] this conclusion is not in harmony with my experience and introspection ... there is plenty of serious and relevant events for which I would not be able to state a probability judgement other than with ample uncertainty: for instance, as regards the likelihood of total war in a near future (L. J. Savage to B. de Finetti, September 1961, as reported in de Finetti and Savage 1962, p. 130 , author's translation from the original Italian).

The issue at stake may appear a descriptive one, but the section on Smith's approach hints at normative issues. De Finetti and Savage admit that Smith's "particularly elaborate analysis" of Koopman's and Good's idea “to make imprecision precise" provides a precise criterion to determine

Smith never appeared in English (excerpt reproduced here are translations from the Italian original made by the author). For a detailed analysis of the genesis of de Finetti and Savage (1962) see Feduzi et al. (2014), on which this section partly draws. 
the two limiting probability values: "In Smith's case ... the objections about the precision of the extreme values do not hold, because he gives a criterion that is ... surely "precise"' (de Finetti and Savage 1962, p. 135). Moreover, de Finetti and Savage (1962, p. 141) accept Smith's considerations about the meaning of being reluctant to betting, since these considerations can refer to "what can be said of a certain behavior when a person has an incomplete knowledge of the opinions justifying a decision."

This reference to incomplete self-knowledge entails a concession to a possible normative justification of using interval-valued probabilities. In fact, it is illustrated through the analogy with the case of a group of decision-makers who have to make a collective decision on the basis of their sharp, but not necessarily unanimous priors - indeed typically different, since "personal" in the subjective approach. In this case, de Finetti and Savage acknowledge, there is a theoretical, not concrete difficulty in determining a single (collective) prior. ${ }^{30}$ And this is dubbed as analogous to the situation of an individual who has "various souls leaning towards contrasting opinions," possibly because she is in doubt about whether to rely on her own sharp prior or on "the ones she has been made aware by consulting experts she considers highly." (de Finetti and Savage 1962, p. $142) .^{31}$

30 Both in his appraisal of Wald (Savage 1951) and in the second part of his Foundations (Savage 1954, ch. 10), Savage did not tackle the issue of group decision making within a proper subjectivist perspective. Indeed, within it there is no obvious way to reconcile individual, personal priors. As noted by Giocoli (2013, pp. 84-85), in order to get to a rule that a group should adopt when making decisions Savage admitted that it was necessary to rely on Wald's minimax rule. De Finetti had autonomously come to the same discomforting conclusion in de Finetti (1954).

31 This example corresponds to what economists today would call a situation of conflicting evidence (Smithson 1999). Situations of this kind are of course quite common in practical decision situations, but may also be considered a failure of subjective-Bayesian rationality. 
The correspondence between de Finetti and Savage in the early 1960s is punctuated by scattered, but recurrent reference to the issue. For instance, while summarizing the last changes about Smith he had made to the draft of their joint paper, de Finetti writes to Savage:

The intuition I have used here ... exemplifies many aspects I understand we should clarify in order to show how to move from a single probability assessment to many (from individual to collective preferences, etc.); so to say, Social choice and individual values under Uncertainty [in English] ... I think something of Smith survives in such a purview (B. de Finetti to L. J. Savage, November 15, 1961, LJS Papers, 7, 193; author's translation from the original Italian).

To this point, Savage replies with a clear reference to the issue of how to deal with probability priors when more than a single one is admitted:

If upper and lower probabilities are taken seriously, they at least double the vagueness that they intended to alleviate ... Nevertheless, I agree that there is practical importance in exploring the implication of a set of probabilities that might be designed as "acceptable" ... I would expect convexity to be an innocuous assumption about a set of acceptable probabilities, and a convex set of probabilities can be well described by inequalities on expectations

(L. J. Savage to B. de Finetti, February 23, 1962, LJS Papers, 8, 194)

The admission that a phenomenon that the subjective viewpoint contemplates as obvious for group decision-making — that the arbitrary opinions of different individuals may not coincide — may also hold true for a single individual, represents a significant concession to Smith's developments and to the other critics of a strict version of the subjective-Bayesian approach. Under the behavioral perspective suggested by Smith, Savage appears to allow vagueness of the beliefs of an individual agent even from a normative perspective, a concession that cannot be retrieved in his published works in English.

Ellsberg ([1962] 2001) identified conflicting evidence as one of the causes justifying deliberate violations of Savage's axioms. In statistical literature, Walley (1991, p. 214) lists the conflict between expert opinions as a notable example of "imprecision [that] reflects unavoidable indeterminacy rather than incomplete modelling." 
As a matter of fact, during discussion with de Finetti about a new joint work that never came out in print, Savage raised the issue at least once more:

We, in the Castellano paper [de Finetti and Savage 1962] repeatedly affirm that anyone who does not act in accordance with some prior distribution exposes himself to unnecessary loss. This thesis seems to me somewhat exaggerated, but of course I hope I am wrong in saying so .... What I seem to be asking for is a derivation of the theory of personal probability as complete and rigorous as that in F. of S. but substantially more convincing and clearer in its practical implications.

(L. J. Savage to B. de Finetti, April 22, 1964, LJS Papers, 8, 198)

Even though Savage's philosophical papers of the late 1960s do not offer any further substantial concession on vagueness, the correspondence suggests that his final position may have been open to a formally consistent representation of it. ${ }^{32}$

\section{CONCLUDING REMARKS}

Contemporary decision theory under uncertainty has built on the so-called Ellsberg Paradox to justify theories that reject, on normative grounds, one of the main tenets of the mainstream subjective-Bayesian approach, namely, that individuals have precise probabilistic beliefs over any source of uncertainty (Gilboa et al. 2008). This point was originally made in the early 1960 s, when Ellsberg and other critics such as Fellner and Smith argued that the subjective-Bayesian model was too restrictive in its assumptions. These critics considered themselves supporters of the subjective view of probability and decision-making, but they could not understand Savage's insistence on the strict version he shared with de Finetti. Their attack was directed to Savage's axiomatic justification

32 Further evidence is provided by the correspondence with de Finetti concerning the drafting of de Finetti's (1967) entry on probability interpretations for the International Encyclopaedia of Social Sciences, a paper written in mid-1962 in which Smith's position is given prominent attention. On this point see Feduzi et al. (2017). 
of the new paradigm, that in the early 1960s was already regarded by the majority of decision theorists so compelling that it could attain the status of the mainstream view in decision theory and economics.

To what extent was Savage ready to admit a permissive variation of his theory of decisionmaking, such as the one suggested in quite similar fashion by Ellsberg, Fellner and Smith in the early 1960s? The abandonment of one of the building blocks of the subjective-Bayesian approachthe representation of degrees of belief through a sharp probability prior-was never endorsed in his published writings, although he admitted that he found this kind of representation wanting on descriptive grounds. However, the doubts he shared in private correspondence with his critics appear to be extremely relevant since they have normative content.

This paper has documented that in his correspondence with what can be identified as a small group of inside critics of the subjective-Bayesian approach — and at the same time with his coauthor de Finetti about how to deal with them-Savage openly examined the issue of how rational choice might be modified when a single individual has less than full understanding of the decision context. The correspondence shows that he never equated Ellsberg's counterexample with Allais's, suggesting that he found the former more puzzling than the later. And that when pressed by Fellner about the implausibility of the sure-thing principle, he suggested a methodological way forward, admitting that normative progress could be envisaged. Moreover, when facing Smith's operational justification of the criticism, he did not regard as untenable a variant of the subjective approach allowing for interval-valued probability priors.

It can then be concluded that Savage's reluctance to endorse the critical viewpoint underlying the Ellsberg Paradox was related to methodological caution rather than to rejection of its content. The new notion of mathematical rigor he had endorsed as part of the group of mathematical economists and statisticians he had worked with in the 1950s was crucial to him. His doubts were mostly based on the inability of his critics to provide an alternative theoretical set-up rather than on a clear-cut denial of the normative relevance of their argument. He may have been ready to endorse 
it had a consistent theoretical corpus and the appropriate axioms made available by his critics. He died at 54 , far too early to see such analytical progress come into reality.

\section{REFERENCES}

Allais, Maurice. 1953. "Le comportement de l'homme rationnel devant le risque: critique des postulats et axioms de l'ecole americaine." Econometrica 21 (4): 503-46.

Arrow, Kenneth J. 1951. "Alternative approaches to the theory of choice in risk-taking situations." Econometrica 19 (4): 404-37.

-----. 1958. “Utilities, attitudes, choices: A review note.” Econometrica 26 (1): 1-23.

Blume, Lawrence E., and David Easely. 2008. "Rationality.” In S. N. Durlauf and L. E. Blume, eds., The New Palgrave Dictionary of Economics, 2nd edition. London: Palgrave Macmillan.

Binmore, Ken. 2009. Rational Decisions. Princeton: Princeton University Press.

Bridgman, Percy W. 1927. The Logic of Modern Physics. New York: MacMillan.

Camerer, Colin F. 1995. “Individual decision making.” In J. Kagel, and A. E. Roth, eds., Handbook of Experimental Economics. Princeton: Princeton University Press, pp. 587-703.

Camerer, Colin F., and Martin Weber. 1992. "Recent developments in modelling preferences: uncertainty and ambiguity." Journal of Risk and Uncertainty 5 (4): 325-70.

Cowles Commission for Research in Economics. 1950-51. Rational Decision-Making and Economic Behavior - 19th Annual Report: July 1, 1950 - June 30, 1951.

de Finetti, Bruno. [1937] 1964. "Foresight: its logical laws, its subjective sources.” In H. E. Jr. Kyburg and H. E. Smokler, eds., Studies in Subjective Probability. New York: Wiley, pp. 94158.

-----. 1951. "Recent suggestions for the reconciliation of theories of probability." In J. Neyman, ed., Proceedings of the Second Berkeley Symposium on Mathematical Statistics and Probability. Berkeley: University of California Press, pp. 217-225. 
-----. 1954. "Media di decisioni e media di opinioni." Bulletin of International Statistical Institute, 34: $1-14$.

----. 1967. "Probability: Interpretations." In International Encyclopaedia of Social Sciences. New York: Macmillan, pp. 496-505.

de Finetti, Bruno, and Leonard J. Savage. 1962. "Sul modo di scegliere le probabilità iniziali." Biblioteca del Metron, Serie C 1: 81-147. Reprinted in Savage, Leonard J., The Writings of Leonard Jimmie Savage: A Memorial Selection. Washington, DC: American Statistical Association and Institute of Mathematical Statistics, 1981, pp. 308-381.

Duppe, Till, and Roy E. Weintraub. 2014. Finding equilibrium: Arrow, Debreu, McKenzie and the problem of scientific credit. Princeton: Princeton University Press.

Edwards, Ward, Lindman, Harold, and Leonard J. Savage. 1963. "Bayesian statistical inference for psychological research.” Psychological review 70 (3): 193-242.

Ellsberg, Daniel. 1961. "Risk, ambiguity, and the Savage axioms." Quarterly Journal of Economics 75 (4): 643-69.

----. 1963. “[Risk, Ambiguity, and the Savage Axioms:] Reply.” Quarterly Journal of Economics 77 (2): 336-342.

----. [1962] 2001. Risk, Ambiguity and Decision. New York: Routledge.

-----. 2002. Secrets: A Memoir of Vietnam and the Pentagon Papers. New York: Penguin Books.

Feduzi, Alberto, Runde, Jochen, and Carlo Zappia. 2014. "De Finetti on uncertainty." Cambridge Journal of Economics 38 (1): 1-21.

----. 2017. "De Finetti and Savage on the normative relevance of imprecise reasoning: A reply to Arthmar and Brady.” History of Economic Ideas 25 (1): 211-223.

Fellner, William. 1949. Competition Among the Few. New York: Kelley

-----. 1961. "Distortion of subjective probabilities as a reaction to uncertainty." Quarterly Journal of Economics 75 (4): 670-689.

-----. 1963. "Slanted Subjective Probabilities and Randomization: A Reply to Howard Raiffa and K. R. W. Brewer.” Quarterly Journal of Economics 77 (4): 676-690. 
Fienberg, Stephen E. 2006. “When did Bayesian inference became 'Bayesian'?” Bayesian Analysis $1(1): 1-40$.

Fishburn, Peter C. 1968. "Utility theory.” Management Science 14 (5): 335-378.

Fishburn, Peter C., and Peter Wakker. 1995. "The invention of the independence condition for preferences." Management Science 41 (7): 1130-44.

Friedman, Milton and Leonard J. Savage. 1948. "The utility analysis of choices involving risk." Journal of political Economy 56 (4): 279-304.

----. 1952. "The Expected-Utility Hypothesis and the measurability of utility.” Journal of Political Economy 60 (6) : 463-474.

Gilboa, Itzhak. 2009. Theory of Decision Under Uncertainty. Cambridge: Cambridge University Press.

-----. 2015. "Rationality and the Bayesian paradigm.” Journal of Economic Methodology 22 (3): $312-334$.

Gilboa, Itzhak, and Massimo Marinacci. 2013. “Ambiguity and the Bayesian paradigm.” In D. Acemoglu, M. Arellano, and E. Dekel, eds., Advances in Economics and Econometrics, Vol. I. Cambridge: Cambridge University Press, pp. 179-241.

Gilboa, Itzhak, Andrew Postlewaite, and David Schmeidler. 2008. "Probability and uncertainty in economic modelling." Journal of Economic Perspectives 22 (3): 173-188.

Gillies, Donald. 2000. Philosophical Theories of Probability. London: Routledge

Giocoli, Nicola. 2003. Modeling Rational Agents. Cheltenham: Edward Elgar.

-----. 2013. “From Wald to Savage: Homo Economicus becomes a Bayesian statistician.” Journal of the History of Behavioral Sciences 49 (1): 63-95.

Good, Irving J. 1952. "Rational decisions.” Journal of the Royal Statistical Society, Series B 14 (1): $107-114$

Guala, Francesco. 2000. "The logic of normative falsification: rationality and experiments in decision theory." Journal of Economic Methodology 7 (1): 59-93. 
Hands, D. Wade. 2012. “The positive-normative dichotomy and economics.” In U. Maki, ed., Philosophy of Economics. Amsterdam: Elsevier, pp. 291-240.

Hansen, Lars P. 2014. "Nobel lecture: Uncertainty outside and inside economic models." Journal of Political Economy 122 (5): 945-987.

Herfeld, Catherine. 2018. "From theories of human behavior to rules of rational choice: Tracing a normative turn at the Cowles Commission, 1943-54." History of Political Economy 50 (1): $1-48$.

Heukelom, Floris. 2014. Behavioral Economics: A History. Cambridge: Cambridge University Press.

Hirshleifer, J. 1965. "Investment decision under uncertainty: Choice-theoretic approaches." Quarterly Journal of Economics 79 (4): 509-536.

Jallais, Sophie, and Pierre-Charles Pradier 2005. "The Allais Paradox and its immediate consequences for Expected Utility Theory.” In P. Fontaine and R. Leonard, eds., The Experiment in the History of Economics. London: Routledge, pp. 25-49.

Jeffreys, Harold. 1939. Theory of Probability. Oxford: Oxford University Press.

Kahneman, Daniel. 2003. "Maps of bounded rationality: A perspective on intuitive judgment." American Economic Review 93 (5): 1449-1475.

Keynes, John M. [1921] 1973. A Treatise on Probability. The Collected Writings of John Maynard Keynes, Vol. VII. London: Macmillan.

Knight, Frank H. 1921. Risk, Uncertainty and Profit. Boston: Houghton Mifflin.

Koopman, Bernard O. 1940. "The axioms and algebra of intuitive probability." Annals of Mathematics 41: 269-92.

Koopmans, Tjalling J. 1957. Three Essays on the State of Economic Science. London: McGrawHill.

Kyburg, Henry E. Jr. 1978, “Subjective probability: criticisms, reflections and problems.” Journal of Philosophical Logic 7 (1): 157-180.

Levi, Isaac. 2001. "Introduction.” In Ellsberg [1962] 2001, pp. ix-xxxvii. 
Lindley, Dennis V. 1980. "Savage. His work in probability and statistics.” Annals of Statistics 8 (1): $1-24$.

Luce, Duncan R., and Howard Raiffa. 1957. Games and Decisions. New York: Wiley.

Luce, Duncan R., and David H. Krantz. 1971. "Conditional expected utility.” Econometrica 39 (2): $253-271$.

Machina, Mark J. 2008. "Non-expected utility theory." In S. N. Durlauf and L. E. Blume, eds., The New Palgrave Dictionary of Economics, 2nd edition. London: Palgrave Macmillan.

Machina, Mark J., and Marciano Siniscalchi. 2014. “Ambiguity and ambiguity aversion.” In M. J. Machina, and W. K. Viscusi, eds., The Handbook of the Economics of Risk and Uncertainty, Vol. I. Amsterdam: Elsevier, pp. 729-807.

Marschak, Jacob. 1950. "Rational behavior, uncertain prospects, and measurable utility." Econometrica 18 (1): 111-42.

Mongin, Philippe. 2019. "The Allais Paradox: what it became, what it really was, what it now suggests to us." Economics and Philosophy 35 (3): 423-459.

Moscati, Ivan. 2016. "Retrospectives. How economists came to accept expected utility theory. The case of Samuelson and Savage.” Journal of Economic Perspectives 30 (2): 219-236.

Raiffa, Howard. 1961. "Risk, ambiguity, and the Savage axioms: a comment." Quarterly Journal of Economics 75 (4): 690-694.

-----. 1968. Decision Analysis. Introductory Lectures on Choices under Uncertainty. Reading: Addison-Wesley.

Raiffa, Howard and Robert Schlaifer. 1961. Applied Statistical Decision Theory. Boston: Harvard University Press.

Ramsey, Frank P. [1931] 1964. "Truth and probability.” In H. E. Jr. Kyburg and H. E. Smokler, eds., Studies in Subjective Probability. New York: Wiley, pp. 94-158.

Roberts, Harry. 1963. "Risk, ambiguity, and the Savage axioms: a comment." Quarterly Journal of Economics 77 (2): 327-36. 
Samuelson, Paul A. 1966. “Postscript.” In J. E. Stiglitz, ed., The Collected Scientific Papers of Paul A. Samuelson, Vol I. Cambridge, MA: MIT Press, pp. 124-26.

Savage, Leonard J. 1950. "The role of personal probability in statistics.” Econometrica 18 (2): $183-$ 184.

----. 1951. "The theory of statistical decision." Journal of the American Statistical Association 46 (253): 55-67.

-----. 1952. "Une axiomatisation du comportement raisonnable face à l'incertitude." Économétrie 29-33.

-----. 1954. The Foundations of Statistics. New York: Wiley.

-----. 1961. "The Foundations of Statistics reconsidered.” In J. Neyman, ed., Proceedings of the Fourth Berkeley Symposium on Mathematical Statistics and Probability, Vol. I. Berkeley: University of California Press, pp. 575-586.

----- 1962a. "Subjective probabilities and statistical practice.” In G. A. Barnard and D. R. Cox, eds., The Foundations of Statistical Inference: A Discussion. London: Methuen, pp. 9-35.

----. 1962b. “Bayesian statistics.” In R. F. Machol and P. Gray, eds., Recent Developments in Decision and Information Processes. New York: MacMillan, pp. 161-194.

----. 1962c. "English Summary.” In de Finetti and Savage 1962, pp. 148-151.

----. 1962d. "Review of C. A. B. Smith 1961.” Mathematical Reviews 23, A1414.

-----. 1967a. "Difficulties in the theory of personal probability." Philosophy of Science 34 (4): 305-310.

----. 1967b. "Implications of personal probability for induction." The Journal of Philosophy 64 (4): 593-607.

-----. 1970. "Reading suggestions for the Foundations of Statistics." The American Statistician 24 (1): 23-27.

Schmeidler, David. 1989. "Subjective probability and expected utility without additivity." Econometrica 57 (3): 571-87. 
Smith, Cedric A. B. 1961. "Consistency in statistical inference.” Journal of the Royal Statistical Society, Series B 23 (1): 1-25.

-----. 1965. "Personal probability and statistical analysis." Journal of the Royal Statistical Society, Series A 128 (4): 469-499.

Smithson, M. (1999). “Conflict aversion: preference for ambiguity vs conflict in sources and evidence." Organizational Behavior and Human Decision Processes 79 (2): 179-198.

von Neumann, John, and Oskar Morgenstern. 1947. Theory of Games and Economic Behavior, $2^{\text {nd }}$ ed. Princeton: Princeton University Press.

Wald, Abraham. 1945. "Statistical decision functions which minimize the maximum risk." Annals of Mathematics 46 (2): 265-280.

Walley, Peter. 1991. Statistical Reasoning with Imprecise Probabilities. London: Chapman and Hall.

Wallis, Allen W. 1980. “Memorial service tribute.” In Savage, Leonard J., The Writings of Leonard Jimmie Savage: A Memorial Selection. Washington, DC: American Statistical Association and Institute of Mathematical Statistics, pp. 11-24.

Zappia, Carlo. 2016. "Daniel Ellsberg and the validation of normative propositions.” Economia 6 (1): 57-79.

-----. 2018. "Rationality under uncertainty: classic and current criticisms of the Bayesian viewpoint." The European Journal of the History of Economic Thought 25 (6): 1387-419. 